\title{
Zerumbone acts as a radiosensitizer in head and neck squamous cell carcinoma
}

\author{
Julia Schnoell ${ }^{1}$ (1) - Isabella Stanisz ${ }^{1} \cdot$ Bernhard J. Jank ${ }^{1}$. Victoria Stanek ${ }^{1} \cdot$ Rainer Schmid $^{2} \cdot$ Markus Brunner $^{1}$. \\ Gregor Heiduschka ${ }^{1}$. Ulana Kotowski ${ }^{1}$
}

Received: 19 August 2021 / Accepted: 28 September 2021 / Published online: 6 October 2021

(c) The Author(s) 2021

\begin{abstract}
Summary
Introduction. Zerumbone is a phytochemical compound of the ginger plant Zingiber zerumbet with cytotoxic effects in various cancer cell lines. To date, zerumbone has shown an antiproliferative effect in oral squamous cell carcinoma cells lines. However, the effect of combination with radiation or cisplatin in head and neck squamous cell carcinoma (HNSCC) is unclear. The aim of this study was to investigate the effect of zerumbone alone, and in combination with irradiation and cisplatin on HNSCC cell lines. Methods. The three HNSCC cell lines SCC25, Cal27 and FaDu were treated with zerumbone, radiation and/or cisplatin. Cell viability and clonogenic assays were performed. The interaction between zerumbone and radiation or cisplatin was evaluated using the combination index. Apoptosis was measured by flow cytometry and cell migration was assessed using a wound healing assay. Results. Treatment with zerumbone resulted in a dose dependent induction of cytotoxicity and apoptosis in all three cell lines. The combination with cisplatin revealed a synergistic to additive effect in Cal27. The clonogenic assay showed a significant radiosensitizing effect in all three cell lines. The wound healing assay showed a reduction of cell migration in Cal27. Conclusion. The natural compound zerumbone shows a cytotoxic and proapoptotic effect on HNSCC cell lines. Furthermore, zerumbone enhances the radiation effect in all three cell lines and thus may be a suitable candidate for combination therapy in HNSCC.
\end{abstract}

Keywords Zerumbone $\cdot$ Natural products $\cdot$ Head and neck squamous cell carcinoma $\cdot$ Cytotoxic $\cdot$ Radiation

\section{Introduction}

Head and neck squamous cell carcinoma (HNSCC) is the sixth most common cancer worldwide with an incidence of approximately 900.000 new cases per year [1]. The average 5 -year survival rate of HNSCC is $66 \%$, but strongly depends on the tumor stage and location [1-3]. The majority of patients are diagnosed with a locally advanced stage which requires a multimodal therapy including surgery, irradiation and/or chemotherapy. However, treatment intensification comes at the cost of adverse effects and is therefore limited

Gregor Heiduschka

gregor.heiduschka@meduniwien.ac.at

Julia Schnoell

julia.schnoell@meduniwien.ac.at

1 Department of Otorhinolaryngology, Head and Neck Surgery, Medical University Vienna, Vienna, Austria

2 Department of Radiotherapy, Medical University of Vienna, Vienna, Austria
[2-4]. Hence, the identification of suitable new substances is required which show antiproliferative effects and ideally help to improve radio- and chemotherapy.

Natural sources play a great role in the discovery of many anticancer drugs. For instance, taxanes and vinca alkaloids were initially isolated from the madagaskar periwinkle and the Pacific yew tree bark, respectively [5]. The advantage of natural products is that they often interact with multiple targets. Thus, they are more promising to show an effect in the dysregulated tumor cell state with alterations in hundreds of genes. Additionally, they are generally safer to use, less expensive and more accessible [6].

Zerumbone is a natural compound of the ginger plant Zingiber zerumbet Smith. In Asian traditional medicine the plant is used to treat a wide variety of diseases and symptoms. The anticancer properties of zerumbone have been reported in several studies in vitro and in vivo in various cancers [7-9]. In contrast to the cytotoxic effect on cancer cells, zerumbone shows only minimal to no effect on normal cells [9-11]. Other properties of zerumbone are 
anti-inflammatory, antioxidant, antiatheroslerotic, antinociceptive, antimicrobial and hepatoprotective activities [8]. Reported mechanisms leading to the antiproliferative effects of zerumbone include the modulation of the Nf- $\mathrm{\kappa B}$ pathway, the mitochondrial pathway of apoptosis, upregulation of redox potential, inhibition of CXC chemokine receptor-4 expression, PI3K-mTOR and TRAIL pathway [7-9].

The aim of this study was to investigate the effect of zerumbone in the HNSCC cell lines SCC25, Cal27 and $\mathrm{FaDu}$ especially in combination with (the standard therapeutic options in HNSCC treatment) cisplatin and irradiation.

\section{Materials and methods}

\section{Drugs}

Zerumbone was obtained from Sigma Aldrich (St. Louis, MO, USA). It was dissolved in dimethyl sulfoxide (DMSO; Sigma Aldrich, St. Louis, MO, USA) as a $100 \mathrm{mmol} / \mathrm{l} \mathrm{stock}$ solution and stored at $-20^{\circ} \mathrm{C}$. Further dilution was done with RPMI medium immediately before treatment. Cisplatin (CIS) was taken from ready-to-use infusions.

\section{Cell culture}

The HNSCC cell line FaDu was obtained from the American Type Culture Collection (Manassas, VA, USA). Cal27 and SCC25 were obtained from the German Collection of Microorganisms and Cell Cultures (Braunschweig, Germany). The cell line $\mathrm{FaDu}$ derived from a human pharyngeal squamous cell carcinoma whereas SCC25 and Cal27 are from human squamous cell carcinomas of the tongue. The cell lines were kept in RPMI medium (Gibco BRL, Gaithersburg, MD, USA) supplemented with $1 \%$ penicillin-streptomycin (Gibco BRL, Gaithersburg, MD, USA) and 5\% fetal bovine serum (Gibco BRL, Gaithersburg, MD, USA) in a humidified atmosphere with $5 \% \mathrm{CO}_{2}$.

\section{Cytotoxicity assay}

A cytotoxicity assay was performed to assess the cytotoxic effect of zerumbone. $3 \times 10^{3}$ cells were seeded on 96-well plates in triplicates and incubated for $24 \mathrm{~h}$. Subsequently, they were treated with $0-96 \mu \mathrm{M}$ zerumbone. For the combination experiments, cells were treated with cisplatin $0-32 \mu \mathrm{M}$ or a combination of zerumbone and cisplatin (ratio 3:1) as well as with irradiation 0-8 Gy alone or in combination with zerumbone. $0,1 \%$ DMSO was used as vehicle control. After $72 \mathrm{~h}$ of incubation the percentage of living cells was assessed using the Cell Counting Kit-8 assay (CCK-8, Dojindo Molecular Technologies Inc., Rockville, MD, USA) according to the manufacturer's protocol.

\section{Flow cytometry analysis}

To assess the induction of apoptosis, flow cytometry analysis was performed. Briefly, $10^{5}$ cells were seeded on 6-well plates and incubated for $24 \mathrm{~h}$. Then, cells were treated with $0,4,8$ and $16 \mu \mathrm{M}$ zerumbone. After $24 \mathrm{~h}$ and $48 \mathrm{~h}$, apoptosis and necrosis were measured using the AnnexinV Apoptosis Detection Kit (Bender MedSystems, Vienna, Austria). Apoptosis was defined as Annexin +/propidium iodide $-(\mathrm{Ann}+/ \mathrm{PI}-)$ and necrosis/late apoptosis was defined as Ann-/PI+ and Ann $+/ \mathrm{PI}+$.

\section{Wound healing assay}

Cells were seeded on 6-well plates and after reaching a confluence of approximately $80 \%$, a scratch was made using a $1 \mathrm{ml}$ pipette tip. After washing twice with warm PBS, cells were treated with $0,5,10$ and $20 \mu \mathrm{M}$ zerumbone. Two regions per scratch were marked and photographed subsequently after the scratch and again after $24 \mathrm{~h}$ of incubation using CellSens Software (version 1.8.1, Olympus Corporation, Tokyo, Japan). The wound healing area was measured using ImageJ macro "MRI Wound Healing Tool" [12].

\section{Irradiation}

Irradiation was carried out using a $150 \mathrm{kV}$ x-ray machine (Gulmay D3300, Gulmay Medical Ltd., Byfleet, UK) at a dose rate of $2 \mathrm{~Gy} / \mathrm{min}$ at room temperature. The focus-object distance measured $52 \mathrm{~cm}$ and the field size was $20 \times 20 \mathrm{~cm}$. Thermoluminescence dosimeters were used for dosimetry assessment.

\section{Clonogenic assay}

The clonogenic assay was performed according to the protocol by Franken et al. [13]. Six-well plates were seeded with 3 to $15 \times 10^{2}$ cells and incubated for $24 \mathrm{~h}$. Next, cells were treated with $0,2.5$ or $5 \mu \mathrm{M}$ zerumbone and/or irradiated with $0,2,4,6$ or $8 \mathrm{~Gy}$ and incubated for $72 \mathrm{~h}$. Afterwards, the medium was replaced with drug-free medium. 10 days later, cells were washed with phosphate-buffered saline, fixed with ethanol $96 \%$ and stained with crystal violet. Colonies containing more than 50 cells were viewed as survivors and counted.

\section{Statistical analysis}

All experiments were carried out at least three independent times. The statistical analysis for cytotoxicity assays and flow cytometry were performed using GraphPad 5.0 software by Prism ${ }^{\circledR}$ (GraphPad Software Inc., San Diego, CA, 
USA). The interaction of zerumbone and cisplatin and short term combination with irradiation were analyzed using the Combination Index according to the Chou-Talalay method using CompuSyn software (ComboSyn Inc.) [14]. The clonogenic assay was analyzed using a linear-quadratic model as described by Franken et al. [13]. Flow cytometry and wound healing assay were analyzed with GraphPad 5.0 software by Prism ${ }^{\circledR}$ using one-way analysis of variance (ANOVA) and Tukey's multiple comparisons test. A p-value below 0.05 was considered as statistically significant.

\section{Results}

\section{Zerumbone leads to inhibition of cell viability}

The three HNSCC cell lines SCC25, Cal27 and FaDu were treated with zerumbone $(0-96 \mu \mathrm{M})$ for $72 \mathrm{~h}$ and cell viability was measured using CCK-8. Treatment with zerumbone showed a dose dependent inhibition of cell viability in all three cell lines (Fig. 1). Cal27 cells were most sensitive to zerumbone treatment with an $\mathrm{IC}_{50}$ at $4.42 \mu \mathrm{M}$, followed by $\mathrm{FaDu}$ cells with an $\mathrm{IC}_{50}$ at $8.60 \mu \mathrm{M}$. SCC25 was the least sensitive cell line with an $\mathrm{IC}_{50}$ at $9.22 \mu \mathrm{M}$.

\section{Treatment with zerumbone induces apoptosis}

Flow cytometry was performed to assess apoptosis and necrosis. Cells were seeded into 6-well plates, treated with $0,4,8$ or $16 \mu \mathrm{M}$ zerumbone and incubated for 48 or $72 \mathrm{~h}$. All three cell lines showed a dose-dependent increase of apoptosis and necrosis (Fig. 2). After $24 \mathrm{~h}$ of incubation, apoptosis was significantly increased in SCC25 at $16 \mu \mathrm{M}$, and in $\mathrm{Cal} 27$ at 8 and $16 \mu \mathrm{M}$. While the amount of necrosis was not affected in SCC25 and FaDu after $24 \mathrm{~h}$, it was significantly increased in $\mathrm{Ca} 27$ at $16 \mu \mathrm{M}$. After $72 \mathrm{~h}$, apoptosis was significantly increased in SCC25 at 8 and $16 \mu \mathrm{M}$ and $\mathrm{FaDu}$ at
Fig. 1 Combination of zerumbone and cisplatin. (a) Cell viability after treatment with zerumbone (ZER), cisplatin (CIS) or the combination of both for $72 \mathrm{~h}$. Treatment concentration is described on the $\mathrm{x}$-axis in $\mu \mathrm{M}$. (b) Combination Index: $\mathrm{CI}<1$ indicates synergy, $\mathrm{CI}>1$ antagonism and $\mathrm{CI}=1$ represents an additive effect. Error bars represent the standard error of the mean a

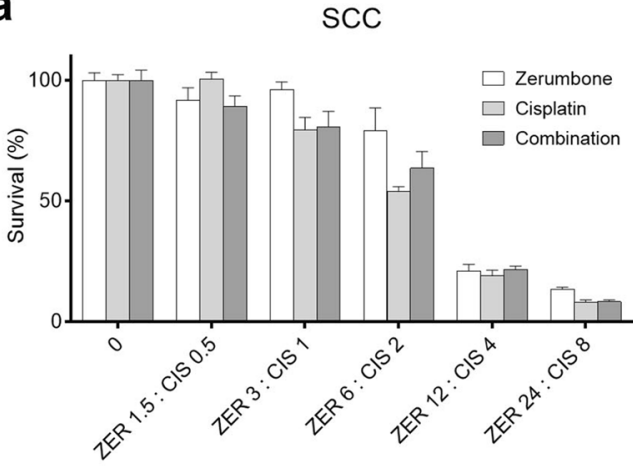

Cal27

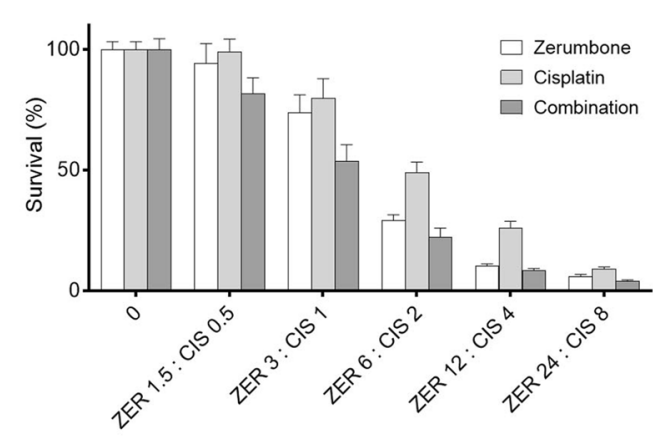

$\mathrm{FaDu}$

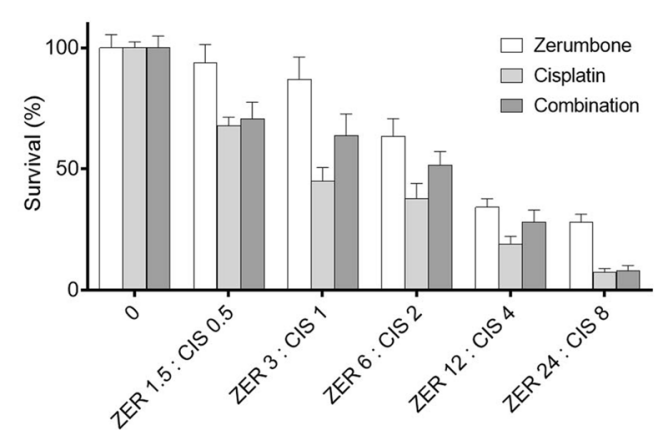

b

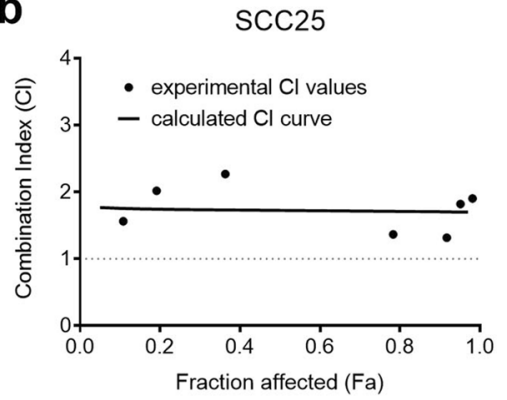

$\operatorname{scC} 25$

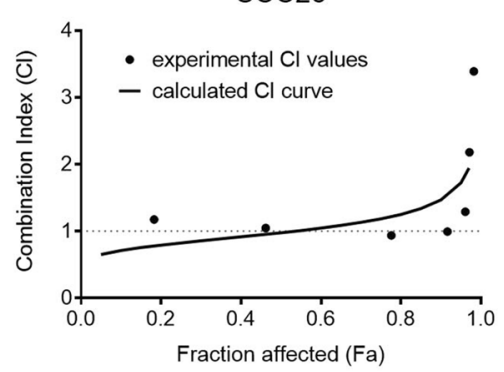

$\operatorname{scC} 25$

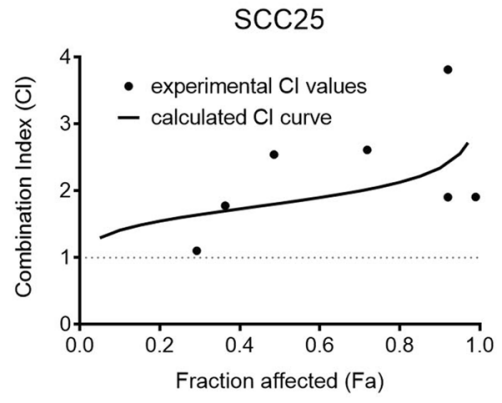


a $48 \mathrm{~h} \quad \operatorname{scc} 25$

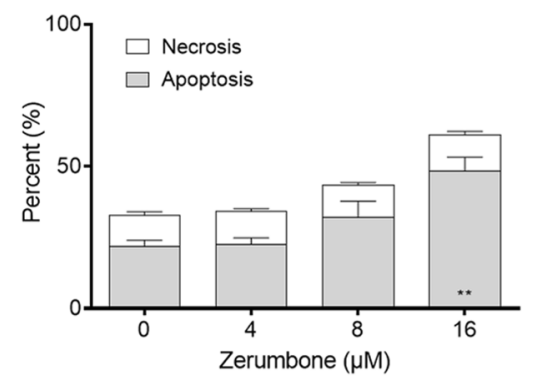

b $72 \mathrm{~h}$

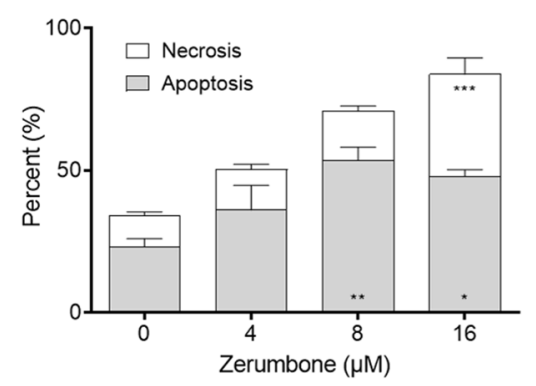

Cal27

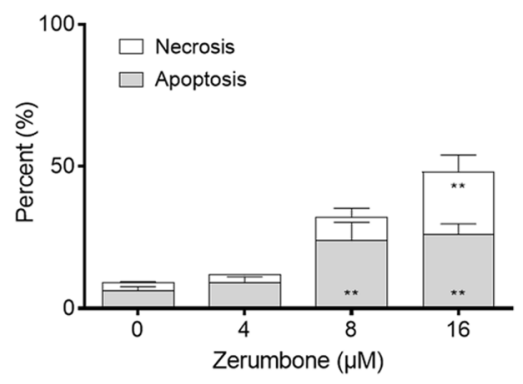

Cal27

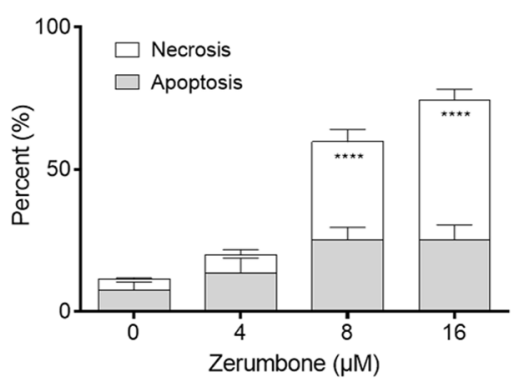

$\mathrm{FaDu}$

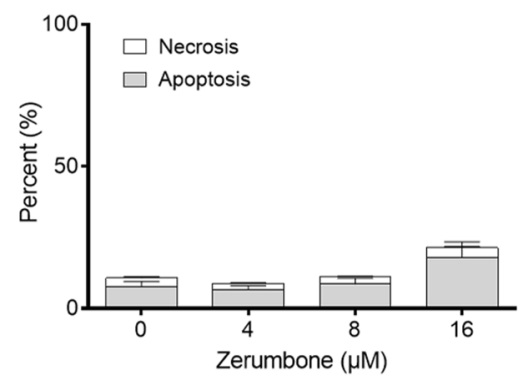

$\mathrm{FaDu}$

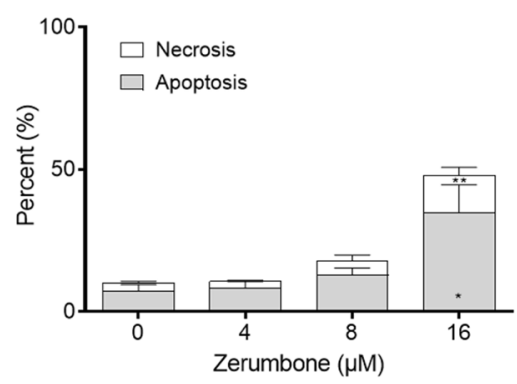

Fig. 2 Flow cytometry analysis of apoptosis and necrosis after (a) $48 \mathrm{~h}$ and (b) $72 \mathrm{~h}$ of incubation with zerumbone. Percentage of apoptosis/necrosis were compared to the control. Error bars represent the

$16 \mu \mathrm{M}$. Furthermore, after $72 \mathrm{~h}$ necrosis was increased in all three cell lines at $16 \mu \mathrm{M}$ and additionally in Cal27 at $8 \mu \mathrm{M}$. However, it should be noted that in this assay late apoptosis is not distinguishable from necrosis. standard error of the mean. *: $\mathrm{p}<0.05 ; * * \mathrm{p}<0.01 ; * * *: \mathrm{p}<0.001$; $* * * *: \mathrm{p}<0.0001$

\section{Wound healing assay}

Cell migration was investigated using the wound healing assay. Cells were seeded onto 6-well plates and a scratch
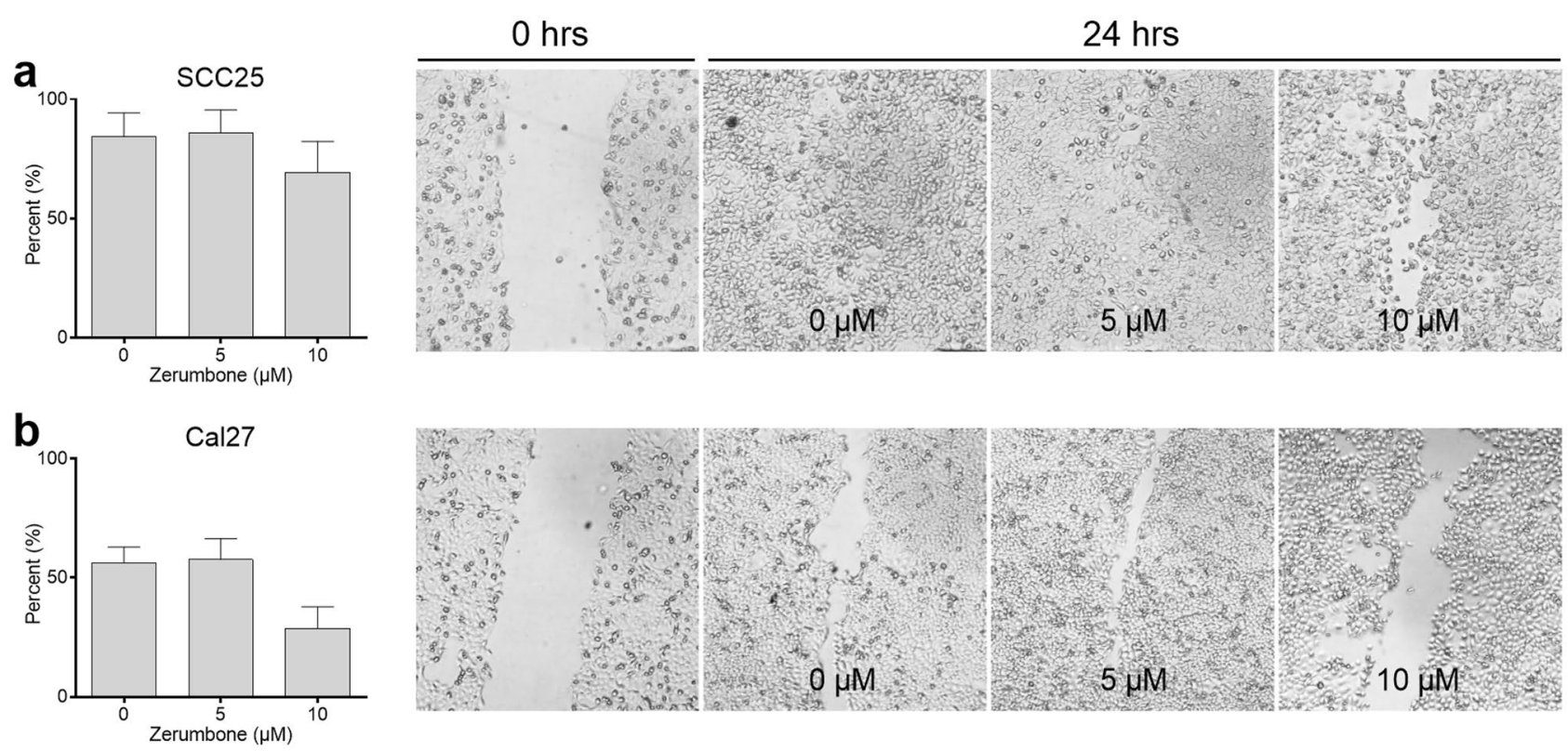

Fig. 3 Wound healing assay of (a) SCC25 and (b) Cal27. Cells were photographed immediately after performing the scratch $(0 \mathrm{~h})$ and after $24 \mathrm{~h}$ of incubation with $0,5,10 \mu \mathrm{M}$ zerumbone. Percentage of migration after $24 \mathrm{~h}$ of incubation was assessed. Error bars represent the standard error of the mean 
was made prior to incubation with zerumbone at $0,5,10$ and $20 \mu \mathrm{M}$ for $24 \mathrm{~h}$. There was a notable difference in the wound healing capacity in SCC25 and in Cal27 at 10-20 $\mu \mathrm{M}$. In $\mathrm{Ca} 27$ the wound healing area has closed by $53 \%$ in the control group and $31 \%$ at $10 \mu \mathrm{M}$ zerumbone. In SCC25 the wound healing area has closed by $84 \%$ in the control group and $69 \%$ at $10 \mu \mathrm{M}$ zerumbone (Fig. 3). Although there was a significant reduction of wound healing in SCC25 and Cal27 at $20 \mu \mathrm{M}$, the overall cell density has markedly decreased due to cytotoxicity (data not shown). Results of $\mathrm{FaDu}$ were not reproducible due to tissue tearing when performing the scratch.

\section{Effect of zerumbone and cisplatin on cell viability}

To determine a possible synergism with the chemotherapeutic agent cisplatin, cells were treated with cisplatin and zerumbone simultaneously at a ratio of 3:1. In Cal27 the combination with zerumbone led to an enhanced effect of cisplatin treatment. In SCC25 and FaDu zerumbone decreased the effect of cisplatin treatment. Next, the results were analyzed with the Combination Index (CI). $\mathrm{CI}<1$ indicates synergy, $\mathrm{CI}>1$ an antagonistic effect and $\mathrm{CI}=1$ represents an additive effect. Treatment combination in $\mathrm{SCC} 25$ and $\mathrm{FaDu}$ a

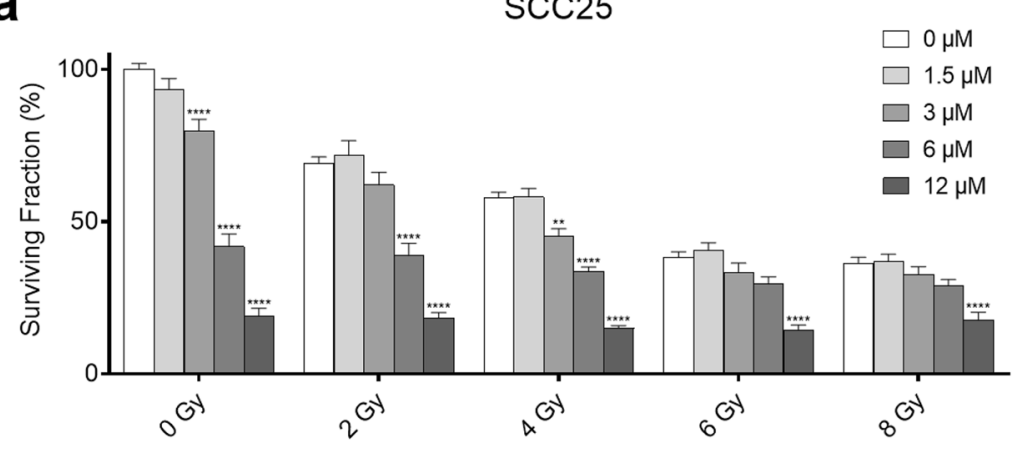

Cal

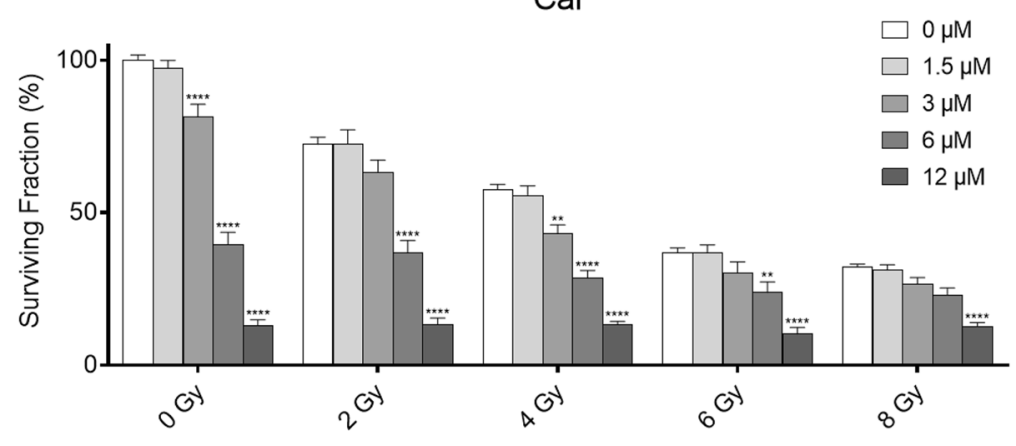

FaDu

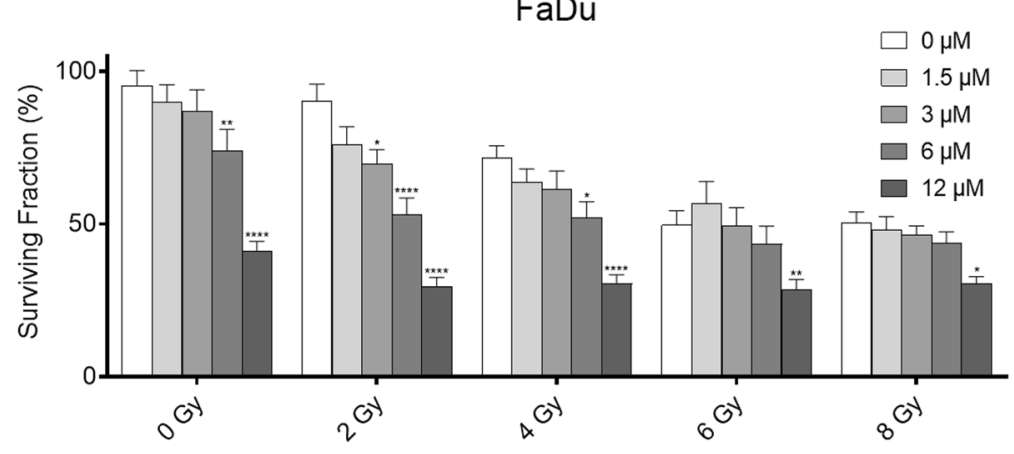

b

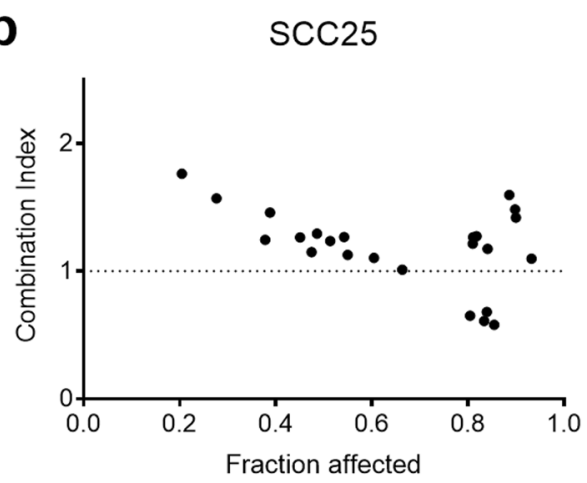

Cal27

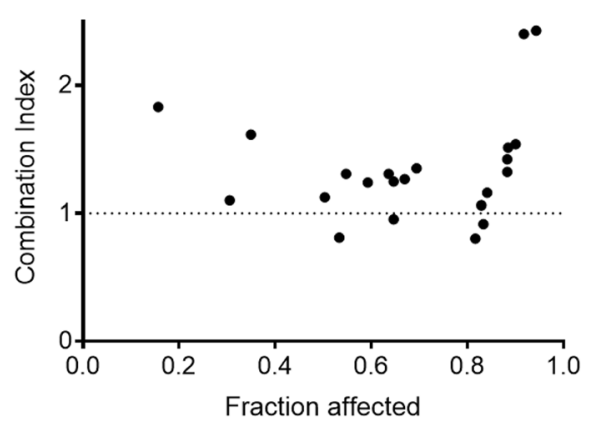

$\mathrm{FaDu}$

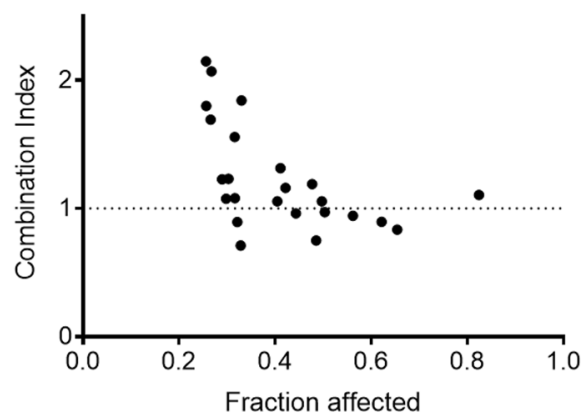

Fig. 4 Combination of zerumbone and irradiation. (a) Survival (\%) after treatment with zerumbone and radiation for 72 h. (b) Experimental CI values of zerumbone and radiation. CI $<1$ indicates synergy, $\mathrm{CI}>1$ antagonism and $\mathrm{CI}=1$ represents an additive effect. Error bars represent the standard error of the mean. Significance levels were compared to the control group within the same radiation dose. $*: \mathrm{p}<0.05 ; * * \mathrm{p}<0.01 ; * * *: \mathrm{p}<0.001 ; * * * *: \mathrm{p}<0.0001$ 
showed an antagonistic effect for all doses. The CI for Cal27 revealed a synergistic to additive effect up to the combination of $4.88 \mu \mathrm{M}$ zerumbone and $1.63 \mu \mathrm{M}$ cisplatin (CI $0.65-$ 1.08) and an antagonism for higher doses (Fig. 1).

\section{Effect of zerumbone and radiation on cell viability and colony formation}

To assess the short-term effect, cells were treated with zerumbone $(0-96 \mu \mathrm{M})$ and irradiation $(0-8 \mathrm{~Gy})$ for $72 \mathrm{~h}$. Treatment with zerumbone enhanced the radiation effect in all three cell lines at different concentrations (Fig. 4). When analyzed with the $\mathrm{CI}$ a synergistic effect was found in SCC25 for $12 \mu \mathrm{M}$ zerumbone and 2-8 Gy (CI 0.570.68). Cal27 showed a slight to moderate synergism when $6-12 \mu \mathrm{M}$ zerumbone were combined with $2-4$ Gy (CI $0.80-0.95)$. FaDu showed a nearly additive or synergistic effect at $1.5-12 \mu \mathrm{M}$ and $2-6 \mathrm{~Gy}$ (CI $0.71-1.1)$.

The long-term effect of combination treatment was assessed with the clonogenic assay. Treatment with zerumbone and/or radiation led to a decrease of clonogenic survival in all cell lines. Moreover, all three cell lines showed a significantly increased inhibition of colony formation at 2.5 and $5 \mu \mathrm{M}$ (all $\mathrm{p}<0.001$, Fig. 5) when analyzed with linear regression according to Franken et al. [13].

\section{Discussion}

HNSCC is one of the sixth most common carcinoma worldwide and survival rate only marginally improved over the last decades. Thus, new treatment options are needed to improve overall survival. The investigation of natural products has led to the discovery of several well-known chemotherapeutic agents. The ginger plant Zingiber zerumbet is commonly used in traditional medicine in Asia to treat a wide variety of symptoms and diseases. Zerumbone is the major component of its essential oil and has been researched in many studies in vivo and in vitro. It shows a cytotoxic effect in cancer cell lines such as lung cancer [15], colorectal cancer [16], leukemia [11] and oral cancer [9]. However, it has minimal to no effect on normal cells $[9,16,17]$.

In this study, the effect of zerumbone on the HNSCC cell lines SCC25, Cal27 and FaDu was investigated. Zerumbone showed antiproliferative effects in all three cell lines with $\mathrm{IC}_{50}$ values between 4.4-9.2 $\mu \mathrm{M}$. Additional flow cytometry analysis showed upregulation of apoptosis in all three cell lines. Migration was reduced in Cal27 at $10 \mu \mathrm{M}$. In concordance, Zainal et al. showed an antiproliferative effect in oral cancer cells between $0.8-4.9 \mu \mathrm{M}$ and a proapoptotic and antimigratory effect [9].

Next, the combinatory effect of zerumbone and cisplatin at a ratio of 3:1 was investigated, since cisplatin is the standard
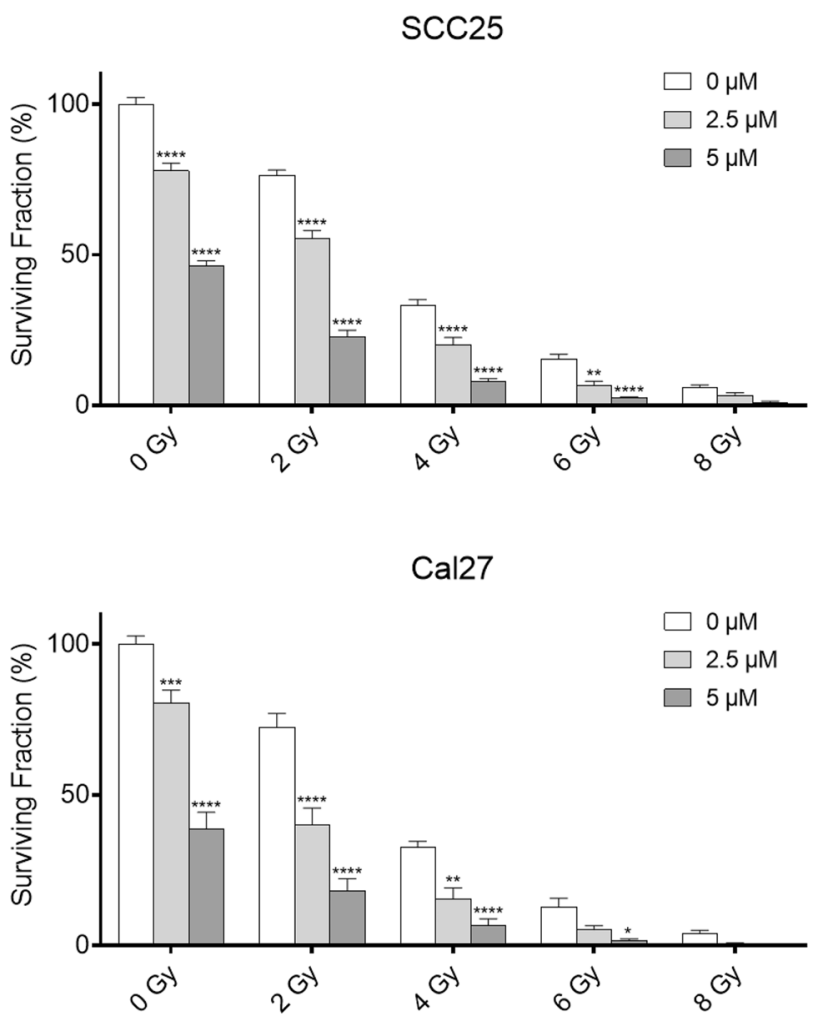

FaDu

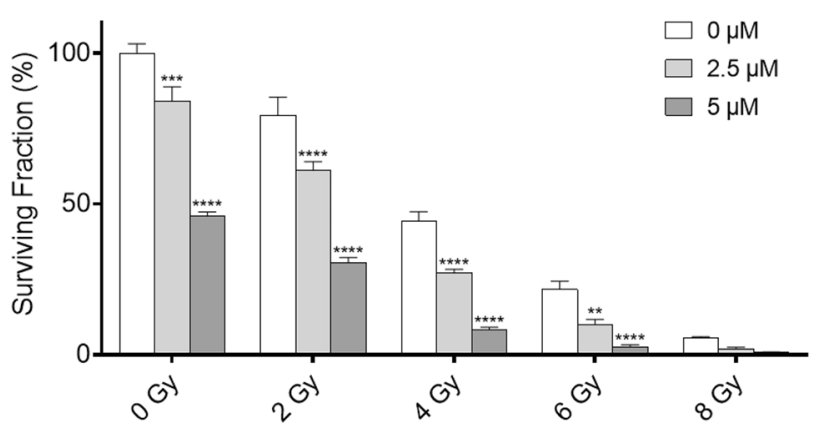

Fig. 5 Clonogenic assay of SCC25, Cal27, and FaDu cells. Cells were treated with $0,2.5$ or $5 \mu \mathrm{M}$ zerumbone and subsequently irradiated with $0,2,4,6$, or 8 Gy. All cell lines showed a significant inhibition of colony formation when analyzed with the linear-quadratic model by Franken et al. (all $p<0.001)$. Error bars represent the standard error of the mean. The indicated significance levels were additionally analyzed using a two-way ANOVA. Treated cells were compared to the control group within the same radiation dose. *: $\mathrm{p}<0.05$; $* * \mathrm{p}<0.01 ; * * *: \mathrm{p}<0.001 ; * * * *: \mathrm{p}<0.0001$

chemotherapeutic agent in HNSCC treatment [18]. Combined treatment showed an antagonistic effect in $\mathrm{SCC} 25$ and $\mathrm{FaDu}$. In Cal27 an additive to synergistic effect for low drug doses was found. However, for cancer therapy synergism at high concentrations is more useful in order to make the most of both substances [14]. Hence, we assume that zerumbone is no suitable candidate for combination with cisplatin in HNSCC. So far, 
only Hu et al. investigated the combinatory effect of zerumbone and cisplatin in vitro on lung cancer cells. In contrast to our study they demonstrated a significantly enhanced growth suppression when both substances were combined [15].

Another pillar of HNSCC treatment is radiotherapy. In this study, combination experiments of zerumbone and radiation showed an additive or synergistic effect at different concentrations in all three cell lines. Furthermore, the clonogenic assay showed a significantly reduced colony formation by combination of both treatments. Likewise, a radiosensitizing effect was found in colorectal carcinoma [16], prostate cancer [19] and glioblastoma cells [20]. Underlying mechanisms include inhibition of radiation-induced activation DNA double-strand break repair via inhibition of ataxia-telangiectasia mutated (ATM) and DNA-dependent protein kinase, catalytic subunit (DNA-PKcs) [16, 19]. Furthermore, treatment with zerumbone alone and in combination with radiation induced cell cycle arrest in G2/M, the most vulnerable phase for radiation and depletion of the cellular antioxidant glutathione [16].

In conclusion, zerumbone shows a cytotoxic and proapoptotic effect, and inhibits cell migration in HNSCC cell lines. Moreover, this is the first study to describe a radiosensitizing effect of zerumbone in HNSCC cell lines. These results implicate that zerumbone might be an attractive treatment option in HNSCC especially in combination with radiation. However, further preclinical and clinical studies are required to assess the full potential of zerumbone.

Abbreviations CCK-8: Cell Counting Kit-8; CIS: Cisplatin; DMSO: Dimethyl sulfoxide; HNSCC: Head and neck squamous cell carcinoma; SEM: Standard error of the mean; ZER: Zerumbone

\section{Acknowledgements Not applicable.}

Authors' contributions J.S. and U.K. contributed to the study design, data collection, statistical analysis and manuscript writing. I.S., B.J.J., V.S., R.S., M.B., and G.H. contributed to the study design, data collection and manuscript revision. All authors critically reviewed and revised the manuscript. All authors read and approved the final manuscript. All authors have neither financial nor ethical conflict of interests.

Funding Open access funding provided by Medical University of Vienna.

Data availability The datasets generated and analyzed during the current study are available from the corresponding author on reasonable request.

Code availability Not applicable.

\section{Declarations}

Ethics approval Not applicable.

Informed consent Not applicable.
Consent for publication Not applicable.

Research involving human participants and/or animals Not applicable.

Conflicts of interest The authors declare no conflict of interests.

Open Access This article is licensed under a Creative Commons Attribution 4.0 International License, which permits use, sharing, adaptation, distribution and reproduction in any medium or format, as long as you give appropriate credit to the original author(s) and the source, provide a link to the Creative Commons licence, and indicate if changes were made. The images or other third party material in this article are included in the article's Creative Commons licence, unless indicated otherwise in a credit line to the material. If material is not included in the article's Creative Commons licence and your intended use is not permitted by statutory regulation or exceeds the permitted use, you will need to obtain permission directly from the copyright holder. To view a copy of this licence, visit http://creativecommons.org/licenses/by/4.0/.

\section{References}

1. Johnson DE, Burtness B, Leemans CR, Lui VWY, Bauman JE, Grandis JR (2020) Head and neck squamous cell carcinoma. Nat Rev Dis Prim 6(1):92. https://doi.org/10.1038/ s41572-020-00224-3

2. Belcher R, Hayes K, Fedewa S, Chen AY (2014) Current treatment of head and neck squamous cell cancer. J Surg Oncol 110(5):551-574. https://doi.org/10.1002/jso.23724

3. Leemans CR, Braakhuis BJM, Brakenhoff RH (2011) The molecular biology of head and neck cancer. Nat Rev Cancer. Nature Publishing Group 11(1):9-22. https://doi.org/10.1038/nrc2982

4. Schlumpf M, Fischer C, Naehrig D, Rochlitz C, Buess M (2013) Results of concurrent radio-chemotherapy for the treatment of head and neck squamous cell carcinoma in everyday clinical practice with special reference to early mortality. BMC Cancer 13(1):610. https://doi.org/10.1186/1471-2407-13-610

5. Safe S, Kasiappan R (2016) Natural Products as Mechanism-based Anticancer Agents: Sp Transcription Factors as Targets. Phyther Res. John Wiley \& Sons, Ltd 30(11):1723-1732. https://doi.org/ $10.1002 /$ ptr.5669

6. Gupta SC, Kim JH, Prasad S, Aggarwal BB (2010) Regulation of survival, proliferation, invasion, angiogenesis, and metastasis of tumor cells through modulation of inflammatory pathways by nutraceuticals. Cancer Metastasis Rev. Springer US 29(3):405434. https://doi.org/10.1007/s10555-010-9235-2

7. Girisa S, Shabnam B, Monisha J et al (2019) Potential of Zerumbone as an Anti-Cancer Agent. Molecules. Multidisciplinary Digital Publishing Institute 24(4):734. https://doi.org/10.3390/ molecules 24040734

8. Rahman HS, Rasedee A, Yeap SK et al (2014) Biomedical Properties of a Natural Dietary Plant Metabolite, Zerumbone, in Cancer Therapy and Chemoprevention Trials. Biomed Res Int Hindawi Publishing Corporation 2014:1-20. https://doi.org/10.1155/2014/ 920742

9. Zainal NS, Gan CP, Lau BF et al (2018) Zerumbone targets the CXCR4-RhoA and PI3K-mTOR signaling axis to reduce motility and proliferation of oral cancer cells. Phytomedicine 39:33-41. https://doi.org/10.1016/j.phymed.2017.12.011

10. Murakami A (2002) Zerumbone, a Southeast Asian ginger sesquiterpene, markedly suppresses free radical generation, proinflammatory protein production, and cancer cell proliferation accompanied by apoptosis: the alpha, beta-unsaturated carbonyl group 
is a prerequisite. Carcinogenesis 23(5):795-802. https://doi.org/ 10.1093/carcin/23.5.795

11. Xian M, Ito K, Nakazato $\mathrm{T}$ et al (2007) Zerumbone, a bioactive sesquiterpene, induces G2/M cell cycle arrest and apoptosis in leukemia cells via a Fas- and mitochondria-mediated pathway. Cancer Sci 98(1):118-126. https://doi.org/10.1111/j.1349-7006. 2006.00362.x

12. MRI Wound Healing Tool. http://dev.mri.cnrs.fr/projects/imagejmacros/wiki/Wound_Healing_Tool

13. Franken NAP, Rodermond HM, Stap J, Haveman J, Bree C van (2016) Clonogenic assay of cells in vitro. Nat Protoc. Nature Publishing Group 1(5):2315-2319. https://doi.org/10.1038/nprot. 2006.339

14. Chou T-C (2006) Theoretical Basis, Experimental Design, and Computerized Simulation of Synergism and Antagonism in Drug Combination Studies. Pharmacol Rev. American Soc Pharmacol Exp Ther 58(3):621-681. https://doi.org/10.1124/pr.58.3.10

15. Hu Z, Zeng Q, Zhang B, Liu H, Wang W (2014) Promotion of p53 expression and reactive oxidative stress production is involved in zerumbone-induced cisplatin sensitization of non-small cell lung cancer cells. Biochimie Elsevier Masson SAS 107:257-262. https://doi.org/10.1016/j.biochi.2014.09.001

16. Deorukhkar A, Ahuja N, Mercado A et al (2015) Zerumbone increases oxidative stress in a thiol-dependent ROS -independent manner to increase DNA damage and sensitize colorectal cancer cells to radiation. Cancer Med 4(2):278-292. https://doi.org/10. 1002/cam4.367
17. Rasedee A, Abdul AB, Zeenathul NA et al (2014) Zerumboneloaded nanostructured lipid carrier induces G2/M cell cycle arrest and apoptosis via mitochondrial pathway in a human lymphoblastic leukemia cell line. Int J Nanomedicine 9(1):527. https://doi. org/10.2147/IJN.S54346

18. Argiris A, Karamouzis MV, Raben D, Ferris RL (2008) Head and neck cancer. Lancet 371(9625):1695-1709. https://doi.org/ 10.1016/S0140-6736(08)60728-X

19. Chiang P-K, Tsai W-K, Chen M et al (2018) Zerumbone Regulates DNA Repair Responding to Ionizing Radiation and Enhances Radiosensitivity of Human Prostatic Cancer Cells. Integr Cancer Ther. SAGE Publications Inc. 17(2):292-298. https://doi.org/10. 1177/1534735417712008

20. Chiang M-F, Chen H-H, Chi C-W et al (2015) Modulation of Sonic hedgehog signaling and WW domain containing oxidoreductase WOX1 expression enhances radiosensitivity of human glioblastoma cells. Exp Biol Med 240(3):392-399. https://doi. org/10.1177/1535370214565989

Publisher's Note Springer Nature remains neutral with regard to jurisdictional claims in published maps and institutional affiliations. 